\title{
ASSESSING SPECTRUM COMPATIBILITY FOR BEYOND-LINE-OF-SIGHT UAS CONTROL AND NON-PAYLOAD COMMUNICATIONS
}

\author{
Robert J Kerczewski and Jeffrey D. Wilson, NASA Glenn Research Center, Cleveland, Ohio \\ William D. Bishop, Verizon, Cleveland, Ohio
}

\begin{abstract}
In order to provide for the safe integration of unmanned aircraft systems (UAS) into the National Airspace System (NAS), the control and non-payload communications (CNPC) link must be highly reliable. A specific requirement is that it must operate using aviation safety radiofrequency spectrum. Two types of links are required - line-of-sight (LOS) using terrestrial-based communications and beyondline-of-sight (BLOS) using satellite communications. The 2012 World Radiocommunication Conference (WRC-12) provided a suitable allocation for LOS CNPC spectrum in the 5030-5091 MHz band which, when combined with a previously existing allocation fulfills the LOS spectrum requirement. The 5030$5091 \mathrm{MHz}$ band is also allocated for BLOS CNPC, but since a significant portion of that band is required for LOS CNPC, additional BLOS spectrum is required. More critically, there are no satellites in operation or in development to provide such services in that band. Hence BLOS CNPC cannot be provided in protected aviation spectrum under current conditions. To fill this gap and enable integration of UAS into the NAS, it has been proposed to allow CNPC to operate over certain Fixed Satellite Service (FSS) bands in which many satellites currently provide commercial services. To enable this, changes in international regulation must be enacted. Agenda Item 1.5 of the 2015 WRC examines the possible regulatory changes needed. As part of the examination process, sharing between potential UAS using satellite communications for BLOS CNPC and other services allocated to the FSS bands being considered must be studied. This paper reviews the technical requirements and approach being undertaken for these sharing studies, with emphasis on study of interference from UAS into digital repeater links operating under the Fixed Service allocation. These studies are being conducted by NASA Glenn Research Center.
\end{abstract}

\section{Introduction}

Many potential applications for civil use of unmanned aircraft system (UAS) have been identified, with additional use concepts emerging almost daily. However, the ability of UAS to operate in the National Airspace System (NAS), in particular in non-segregated airspace, faces many obstacles. The increasing pressure to remove these obstacles has resulted in the establishment of a national goal in the US of enabling UAS to have routine access to the NAS. Among a number of technical barriers that must be overcome to meet this goal is the absence of standard, certifiable communications links supplying the control and non-payload communications (CNPC) function, essentially providing the link over which a pilot on the ground can control the unmanned aircraft (UA). The International Civil Aviation Organization (ICAO) has determined that the CNPC link must operate over protected aviation spectrum. Therefore protected aviation spectrum must be allocated for this function, approved through the processes of the International Telecommunications Union Radiocommunication Sector (ITU-R).

Spectrum requirements have been met for lineof-sight (LOS) CNPC through actions taken at the ITU-R's 2012 World Radiocommunication Conference (WRC-12). However for beyond-line-ofsight (BLOS) CNPC, sufficient protected aviation spectrum has not been allocated. Agenda Item 1.5 (AI 1.5) for the 2015 WRC (WRC-15) looks into the possible use of commercial satellites operating under the Fixed Satellite Service (FSS) allocation to meet spectrum requirements for BLOS CNPC. However since this allocation is not protected aviation spectrum, regulatory issues must be put in place for such use to be approved. This is the primary issue being addressed by AI 1.5. 
Studies are underway and regulatory proposals are being developed to address Agenda Item 1.5. These include characterization of CNPC technical and operational aspects, definition of performance requirements, and studies of spectrum compatibility between CNPC and other services in these bands. NASA's UAS in the NAS Project is contributing to these activities by performing spectrum compatibility and sharing studies between unmanned aircraft satellite earth stations and terrestrial services which share the Ku-Band and Ka-Band spectrum. The compatibility studies being undertaken by NASA are submitted to the preparation process for the 2015 WRC and then refined and updated based on decisions made by the ITU-R meeting participants.

This paper will expand on the background of the BLOS CNPC and spectrum requirements and then focus on the nature of the spectrum compatibility problem, the approach and methodologies being applied to the studies, and example results.

\section{Spectrum Requirements and Solutions}

Spectrum requirements were established with the adoption of Report M.2171 by the ITU-R [1]. In this report, the requirements of $34 \mathrm{MHz}$ for UAS LOS and $56 \mathrm{MHz}$ for UAS BLOS (satellite) were identified. Actions taken at the ITU's WRC-12 have established sufficient spectrum resources to meet the LOS spectrum requirement with a new Aeronautical Mobile (Route) Service $(\mathrm{AM}(\mathrm{R}))$ allocation in the 5030-5091 MHz band combined with a portion of an existing $A M(R) S$ allocation in the 960-1164 MHz band. The BLOS spectrum requirement remains unfulfilled. A previously existing Aeronautical Mobile Satellite (Route) Service (AMS(R)S) allocation in the 5030-5091 MHz band meets a portion of the requirement, however communication satellites required to provide service in this band do not exist and none are currently planned. As a result, the UAS community is searching for a solution to meet the BLOS CNPC needs.

The most likely solution is to use existing satellites operating under the Fixed Satellite Service (FSS), of which many operate in several bands. Given the size of most unmanned aircraft, higher frequency bands are required in order to have antennas small enough to fit onto the aircraft. Therefore the use of FSS in $\mathrm{Ku}$-Band $(12-18 \mathrm{GHz})$ and Ka-Band (26.5-40.0 GHz) for BLOS CNPC has been proposed. Agenda Item 1.5 for the 2015 WRC (WRC-15) examines this proposal and what regulatory requirements would need to be addressed to allow such an application in those bands.

\section{WRC-15 Agenda Item 1.5}

At WRC-12, Resolution 153 was adopted: "To consider the use of frequency bands allocated to the fixed-satellite service not subject to Appendices 30 , $30 \mathrm{~A}$ and $30 \mathrm{~B}$ for the control and non-payload communications of unmanned aircraft systems (UAS) in non-segregated airspaces "

The resolution [2] considers the possible regulatory actions to support the use of FSS frequency bands for the UAS CNPC links ensuring their safe operation, including the necessary studies leading to technical, regulatory and operational recommendations and sharing and compatibility studies with services already having allocations in those bands.

ITU-R has chartered Working Party 5B (WP5B) to develop the documents and proposals for $\mathrm{AI} 1.5$ that will be considered for approval at WRC-15. Sharing studies, including those under development by NASA, are submitted through WP5B.

\section{Sharing Studies for Agenda Item 1.5}

The sharing studies involved in AI 1.5 include several scenarios and frequency ranges in the $\mathrm{Ku}$ and Ka-Band FSS Bands. These were proposed for further study at WRC-12 and subsequently approved for full analysis with results to be shared and reviewed at WRC-15 as AI 1.5. NASA's Glenn Research Center (GRC) has been requested to conduct sharing studies on UAS Control and NonPayload (CNPC) Link 3 and the potential interference, Path $3 \mathrm{~s}$, shown in Figure 1 below. The frequency bands under study for Link 3 are 14.0-14.5 $\mathrm{GHz}$ in $\mathrm{Ku}-\mathrm{Band}$ and $27.5-30.0 \mathrm{GHz}$ in $\mathrm{Ka}-\mathrm{Band}$. 


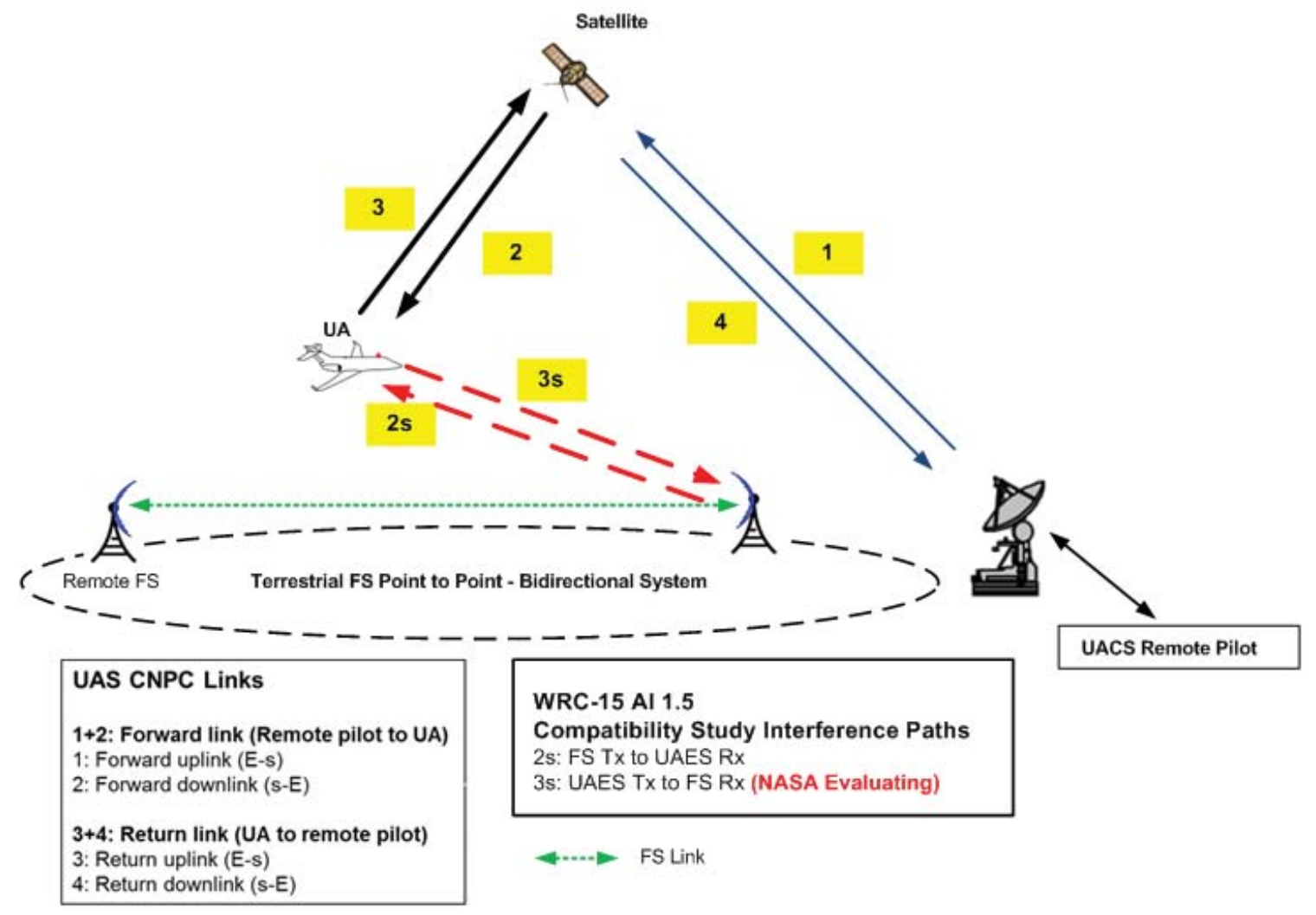

Figure 1. NASA Studying Link 3 and Potential Interference, from [3]

\section{Sharing Study Scenarios for 14.0-14.5 GHz}

Based on the existing allocations in 14.0-14.5 $\mathrm{GHz}$ for terrestrial co-primary services, three interference scenarios exist:

- Interference from UAES uplink transmitters into Fixed Service (FS) (i.e. terrestrial microwave) receivers at $14.3-14.5 \mathrm{GHz}$;

- Interference from UAES uplink transmitters into Mobile Service (MS) (except aero mobile) receivers at 14.3-14.5 GHz;

- Interference from UAES uplink transmitters into Radionavigation Service (RNS) receivers at 14$14.3 \mathrm{GHz}$.

\section{Sharing Studies Conducted Based on Available} System Characteristics for 14.0-14.5 GHz

No technical characteristics of land mobile systems in the land mobile service for the frequency band 14.0-14.5 GHz are available, so no sharing study is being conducted for the mobile service. Similarly WP5B has not identified any current radionavigation uses of the $14.0-14.3 \mathrm{GHz}$ band. Therefore, equipment parameters are not available for consideration in frequency sharing studies and no sharing study is being conducted for the radionavigation service. The sharing study in the 14.0-14.5 $\mathrm{GHz}$ band is therefore limited to interference from UAES (UA Earth Station) uplink transmitters into the fixed service receivers at 14.3$14.5 \mathrm{GHz}$. 
Sharing Study Scenarios for 27.5-30.0 GHz

Based on the allocations, two interference scenarios exist:

- Interference from UA uplink transmitters into Fixed Service (i.e. P-P terrestrial microwave) receivers at $27.5-29.5 \mathrm{GHz}$;

- Interference from UA uplink transmitters into Mobile Service (except aero mobile) receivers at 27.5-29.5 GHz.

There are no fixed, mobile or other terrestrial services allocated in the $29.5-30.0 \mathrm{GHz}$ band, so no sharing studies are needed for this portion of the 27.5-30.0 GHz band.

\section{Sharing Studies Conducted Based on Available System Characteristics for 27.5-30.0 GHz}

No technical characteristics of land mobile systems in the land mobile service for the frequency band 27.5-29.5 GHz are available. Therefore no analysis is conducted for the mobile service.

The sharing study in the $27.5-30.0 \mathrm{GHz}$ band is therefore limited to interference from UA earth station uplink transmitters into the fixed service receivers in 27.5-29.5 GHz.

\section{Flight Scenarios}

Relevant UAS flight scenarios have been provided by the International Civil Aviation Organization for use in the sharing studies [3]. Based on the flight scenario descriptions, scenarios 2 and 7 identify the altitudes required for the sharing studies for the UAES transmitter-FS receiver case as shown in Table 1.

\section{The Sharing Case of UA Earth Station Uplinks}

The ITU-R has established interference criteria to protect the FS from time varying aggregate interference from other radiocommunication services sharing the FS band on a co-primary basis. They have issued recommendations relative to specific frequency bands for both long- and short-term interference. In the studies NASA is performing, the UAES transmit and FS receive characteristics are the primary parameters used in the analysis.
Table 1. UAS Flight Scenarios for Sharing Studies

\begin{tabular}{|l|c|c|}
\hline ICAO Scenario & $\mathbf{2}$ & $\mathbf{7}$ \\
\hline & $\begin{array}{c}\text { Medium } \\
\text { altitude } \\
\text { surveillance/ } \\
\text { Aerial work } \\
\text { (search } \\
\text { pattern) }\end{array}$ & $\begin{array}{c}\text { Departure } \\
\text { Descent } \\
\text { above 3000ft } \\
\text { Above } \\
\text { Ground } \\
\text { Level (AGL) }\end{array}$ \\
\hline $\begin{array}{l}\text { Max altitude } \\
\text { (feet above } \\
\text { MSL, unless } \\
\text { otherwise } \\
\text { specified) }\end{array}$ & 30000 & 19000 \\
\hline $\begin{array}{l}\text { Min altitude } \\
\text { (feet above } \\
\text { MSL, unless } \\
\text { otherwise } \\
\text { specified) }\end{array}$ & 19000 & 3000 \\
\hline $\begin{array}{l}\text { Max latitude } \\
\text { (deg) }\end{array}$ & 70 & 70 \\
\hline
\end{tabular}

UA Earth Station Transmit and Fixed Service Receive Parameters

The UA earth station transmit parameters that are applied to sharing studies for AI 1.5 are being developed through WP5B. The parameter values under consideration can be found in Annex 25 of [3]. Antenna parameters and transmit powers have been specified for antenna diameters of $0.45,0.8$ and 1.25 $\mathrm{m}$ for both the 14.0-14.5 GHz and 27.5-29.5 GHz bands. The FS parameters applied to the sharing are derived primarily from [4] for the $14.0-14.5 \mathrm{GHz}$ and 27.5-29.5 GHz bands.

\section{Distribution of $U A$}

The number and distribution of UA are defined in [1]. The UA density projections for the 2030 time-frame based on estimated UAS usage rates in both the commercial and government sectors is described in Table 2. Based on the flight scenarios that will be studied, the total of the medium and large UA densities are considered, since small UA operate only below $3000 \mathrm{ft}$. For the sharing studies, UA are randomly distributed in an area bounded by the radio horizon relative to an FS receiver using the relative densities shown in Table 2. 
Table 2. UAS Traffic Distribution

\begin{tabular}{|c|c|c|c|c|c|}
\hline Type & Altitude & $\mathbf{U A} / \mathbf{k m}^{2}$ & $\mathbf{U A} / \mathbf{1 0 , 0 0 0 \mathbf { k m } ^ { 2 }}$ & $\begin{array}{c}\text { UA/Spot } \\
\text { Beam }\end{array}$ & $\begin{array}{c}\text { UA/Regional } \\
\text { Coverage Beam }\end{array}$ \\
\hline Medium & $300-5500 \mathrm{~m}$ & 0.000195 & 1.950 & 93 & 1515 \\
\hline Large & $>5500 \mathrm{~m}$ & 0.000044 & 0.440 & 21 & 341 \\
\hline
\end{tabular}

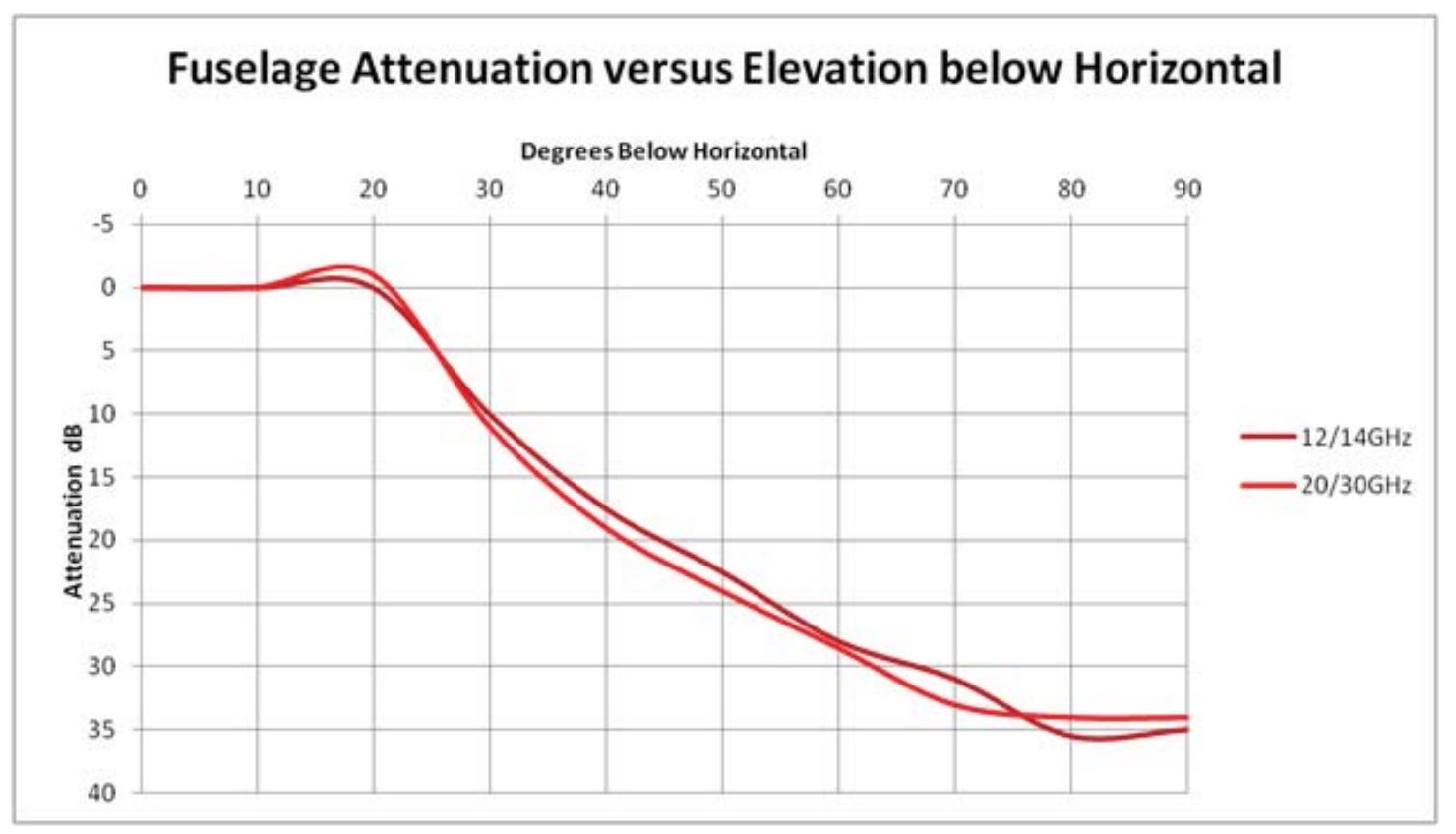

Figure 2. Example Off-Axis Attenuation plot due to the fuselage of the Aircraft (measurements were made at $14.2 \mathrm{GHz}$ )

\section{Fuselage Attenuation}

The fuselage of the UA can provide significant attenuation of the signal between the earth station mounted on the top of the UA and systems on the ground. Figure 2 depicts the calculated fuselage attenuation factored into the analysis as a function of elevation angle of the UAES antenna and frequency.

\section{Protection Criteria for Fixed Service Stations}

Table 3 provides the long and short term protection criteria for the fixed service receivers for the 14.0-14.5 GHz and 27.5-29.5 GHz bands.

\section{Sharing Study Approach}

Visualyse Professional software [5] was used to create models of a number of scenarios involving interference to FS's from UA. These scenarios were used to analyze both long term and short term interference criteria at $\mathrm{Ku}$-band and Ka-band frequencies, with small and large UA antennas, UA altitudes from 3000 to 19000 feet, and FS locations from $10^{\circ} \mathrm{N}$ to $70^{\circ} \mathrm{N}$. For the Ku-band calculations, the antennas were centered at $14.4 \mathrm{GHz}$. The FS antenna has a diameter of $1.2 \mathrm{~m}$, efficiency of 0.6 , and an ITU-R F.699-7 gain rolloff [3, 6]. 
Table 3. Protection criteria for the fixed service in the 14.0-14.5 and 27.5-29.5 GHz Bands

(Input to FS receiver)

\begin{tabular}{|c|c|c|c|l|}
\hline Parameter & $\begin{array}{c}\text { Frequency } \\
\text { Range }\end{array}$ & Value & $\begin{array}{c}\text { ITU-R } \\
\text { Source } \\
\text { Document }\end{array}$ & \multicolumn{1}{|c|}{ Comments } \\
\hline I/N (Long Term) & Both & $-10 \mathrm{~dB}$ & F.758-5 [4] & $\begin{array}{l}\text { Not to exceed for more } \\
\text { than 20\% of the year }\end{array}$ \\
\hline I/N (Short Term) & $\mathrm{Ku}$ & $+20 \mathrm{~dB}$ & $\mathrm{~F} .1494[8]$ & $\begin{array}{l}\text { Not to exceed for more } \\
\text { than 1x10 } \% \text { of the time. }\end{array}$ \\
\hline I/N (Short Term) & $\mathrm{Ka}$ & $+14 \mathrm{~dB}$ & F.1495-2 [9] & $\begin{array}{l}\text { Not to exceed for more } \\
\text { than 0.01\% of the time in } \\
\text { any month. }\end{array}$ \\
\hline I/N (Short Term) & $\mathrm{Ka}$ & $+18 \mathrm{~dB}$ & F.1495-2 [9] & $\begin{array}{l}\text { Not to exceed for more } \\
\text { than 0.0003\% of the time } \\
\text { in any month. }\end{array}$ \\
\hline
\end{tabular}

The Ku-band UA small antenna has a diameter of $0.45 \mathrm{~m}$, efficiency of 0.55 , an ITU-R S.580-6 rolloff, and an equivalent isotropic radiated power (e.i.r.p.) density of $43.78 \mathrm{dBW} / 250 \mathrm{kHz}$. The Ku-band UA large antenna has a diameter of $1.25 \mathrm{~m}$, efficiency of 0.55 , an ITU-R S.580-6 gain rolloff, and an e.i.r.p density of $57.68 \mathrm{dBW} / 250 \mathrm{kHz}[3,7]$.

For the Ka-band calculations, the antennas were centered at $28.5 \mathrm{GHz}$. The FS antenna has a diameter of $0.3 \mathrm{~m}$, efficiency of 0.6 , and an ITU-R F.699-7 gain rolloff $[3,6]$. The Ka-band UA small and large antennas have the same diameters, efficiency, and rolloff as the Ku-band antennas. The Ka-band UA small antenna has an e.i.r.p. density of 42.38 $\mathrm{dBW} / 250 \mathrm{kHz}$ and the Ka-band UA large antenna has an e.i.r.p. density of $48.08 \mathrm{dBW} / 250 \mathrm{kHz}$.

\section{Long Term Interference Criteria}

For the long term interference criterion, we use guidance from Table 4 of [4] which recommends that the aggregate interference to noise ratio $\mathrm{I} / \mathrm{N}$ be less than $-10 \mathrm{~dB}$ for frequencies above $3 \mathrm{GHz}$. In the Visualyse calculations, we placed the FS at specific locations and populated the surrounding airspace with 300,000 randomly located UA's. The FS antenna azimuthal and elevation angles were randomly assigned values from -180 to +180 degrees and -5 to +5 degrees respectively. The expected percentage of time that $\mathrm{I} / \mathrm{N}$ exceeds $-10 \mathrm{~dB}, \mathrm{P}$, is then

$$
\mathrm{P}=\mathrm{QRA} \rho
$$

where $\mathrm{Q}$ is the percentage of the locations that contributed an $\mathrm{I} / \mathrm{N}$ of greater than $-10 \mathrm{~dB}$ to the $\mathrm{FS}$; $\mathrm{R}$ is the probability ratio that a UA is transmitting in a channel that is within the FS bandwidth (for the $\mathrm{Ku}$-band cases, the FS has a maximum bandwidth of $28 \mathrm{MHz}$, thus the probability that a UA is transmitting at a channel that is within the FS bandwidth is $28 / 500=0.056$; for the Ka-band cases, the FS maximum bandwidth is $112 \mathrm{MHz}$, thus the probability that a UA is transmitting at a channel that is within the FS bandwidth is $112 / 2000=0.056$, the same as for Ku-band), A is the airspace area; and $\rho$ is the projected UA traffic density from Table 2, 2.39 $\mathrm{UA} / 10,000 \mathrm{sq} \mathrm{km}$.

UA altitudes of 3000 and 19000 feet and UA small and large antennas were modeled with FS locations at 10, 40, and 70 degrees $\mathrm{N}$. The results for the Ku-band cases are shown in Table 4 and for the $\mathrm{Ka}$-band cases in Table 5. In all the Ku-band cases, the percentage of time that $\mathrm{I} / \mathrm{N}$ is over the threshold of $-10 \mathrm{~dB}$ is less than $0.8 \%$, far below the protection criterion value of $20 \%$. In all the Ka-band cases except two, there were no instances of $\mathrm{I} / \mathrm{N}$ over the threshold. The only cases with $\mathrm{I} / \mathrm{N}$ instances over the threshold were the small and large UA antenna cases for an altitude of 3000 feet at $70^{\circ} \mathrm{N}$. But in these two cases the percentage of time over the threshold was only $0.02 \%$, also far below the protection criterion value of $20 \%$. 
Table 4. Percentage of time $\mathrm{I} / \mathrm{N}$ is worse than $-10 \mathrm{~dB}$ for $\mathrm{FS}$ with bandwidth of $28 \mathrm{MHz}$ with feeder loss = $6 \mathrm{~dB}$ and polarization loss $=0$ for $\mathrm{Ku}$-band. Also shown are the worst values of $\mathrm{I} / \mathrm{N}$.

\begin{tabular}{|c|c|c|c|c|c|}
\hline Case & Altitude (ft) & Antenna Size & $\begin{array}{c}\text { Latitude } \\
(\text { degrees })\end{array}$ & $\begin{array}{c}\text { Percentage Time over } \\
\text { Interference Threshold (\%) }\end{array}$ & $\begin{array}{c}\text { Worst I/N } \\
(\mathrm{dB})\end{array}$ \\
\hline 1 & 3000 & Small & 10 & 0.13 & 4.07 \\
\hline 2 & 3000 & Large & 10 & 0.31 & 9.07 \\
\hline 3 & 3000 & Small & 40 & 0.15 & 4.35 \\
\hline 4 & 3000 & Large & 40 & 0.38 & 9.35 \\
\hline 5 & 3000 & Small & 70 & 0.76 & 8.21 \\
\hline 6 & 3000 & Large & 70 & 0.14 & -3.75 \\
\hline 7 & 19000 & Small & 10 & 0.24 & 1.25 \\
\hline 8 & 19000 & Large & 10 & 0.17 & -2.92 \\
\hline 9 & 19000 & Small & 40 & 0.37 & 2.08 \\
\hline 10 & 19000 & Large & 40 & 0.41 & -1.33 \\
\hline 11 & 19000 & Small & 70 & 0.72 & 3.67 \\
\hline 12 & 19000 & Large & 70 & & \\
\hline
\end{tabular}

Table 5. Percentage of time $\mathrm{I} / \mathrm{N}$ is worse than $-10 \mathrm{~dB}$ for $\mathrm{FS}$ with bandwidth of $112 \mathrm{MHz}$ with feeder loss $=$ $0 \mathrm{~dB}$ and polarization loss $=0$ for Ka-band. Also shown are the worst values of $\mathrm{I} / \mathrm{N}$.

\begin{tabular}{|c|c|c|c|c|c|}
\hline Case & Altitude (ft) & Antenna Size & $\begin{array}{c}\text { Latitude } \\
\text { (degrees) }\end{array}$ & $\begin{array}{c}\text { Percentage Time over } \\
\text { Interference Threshold (\%) }\end{array}$ & $\begin{array}{c}\text { Worst I/N } \\
(\mathrm{dB})\end{array}$ \\
\hline 13 & 3000 & Small & 10 & 0 & -12.86 \\
\hline 14 & 3000 & Large & 10 & 0 & -15.96 \\
\hline 15 & 3000 & Small & 40 & 0 & -10.20 \\
\hline 16 & 3000 & Large & 40 & 0.02 & -13.30 \\
\hline 17 & 3000 & Small & 70 & 0.02 & -0.83 \\
\hline 18 & 3000 & Large & 70 & 0 & -3.93 \\
\hline 19 & 19000 & Small & 10 & 0 & -23.04 \\
\hline 20 & 19000 & Large & 10 & 0 & -18.64 \\
\hline 21 & 19000 & Small & 40 & 0 & -21.74 \\
\hline 22 & 19000 & Large & 40 & 0 & -17.36 \\
\hline 23 & 19000 & Small & 70 & 70 & -20.46 \\
\hline 24 & 19000 & Large & & 0 & 0 \\
\hline
\end{tabular}




\section{Short Term Interference Criteria}

The short term interference criterion at Ku-band is that $\mathrm{I} / \mathrm{N}$ should exceed $20 \mathrm{~dB}$ no more than 0.0001 $\%$ of the time from Table 3. For Ka-band, from Table 3 it is that " $\mathrm{I} / \mathrm{N}$ should not exceed $+14 \mathrm{~dB}$ for more than $0.01 \%$ of the time in any month" and "should not exceed $+18 \mathrm{~dB}$ for more than $0.0003 \%$ of the time in any month".

In the Visualyse calculations, we again placed the FS at specific locations and populated the surrounding airspace with 300,000 randomly located UA. The Visualyse simulations were performed as in the Long Term Interference Criteria section, except that the worst possible scenario was modeled with the FS antenna azimuthal direction pointing northward and the elevation angle at the worst value between -5 to +5 degrees which is +5 degrees.

Simulations were performed at FS latitudes from $10^{\circ} \mathrm{N}$ to $70^{\circ} \mathrm{N}$ in 100 intervals and at UA altitudes from 3000 to 19000 feet in 1000 feet intervals. The minimum UA altitude that avoids exceeding the interference threshold is shown in Fig. 3 for the large UA antenna at Ku-band and in Fig. 4 for the small $\mathrm{UA}$ antenna at $\mathrm{Ku}$-band. For the large $\mathrm{Ku}$-band antenna we see that the threshold altitude drops rapidly from 18,000 feet at $70^{\circ}$ to 7000 feet at $50^{\circ}$ to 6000 feet at $30^{\circ}$ and lower. For the small Ku-band antenna we see that the threshold altitude drops rapidly from 10,000 feet at $70^{\circ}$ to 4000 feet at $50^{\circ}$ to 3000 feet at $10^{\circ}$. For the Ka-band cases, an altitude of 3000 feet was sufficient to stay under the interference threshold at all latitudes for both large and small UA antennas.

\section{Interpretation of Results}

The sharing studies described above, as well as characterization of CNPC technical and operational aspects, definition of performance requirements, and proposed regulatory changes to enable UAS CNPC over FSS satellites are described in draft documents being reviewed and updated in an iterative process through several WP5B meetings occurring between WRC-12 and WRC-15. In regards to the sharing studies in particular, agreement within WP5B on technical characteristics of CNPC, CNPC performance requirements, and appropriate protection criteria and technical characteristics of other systems in the bands being studies is still being developed.

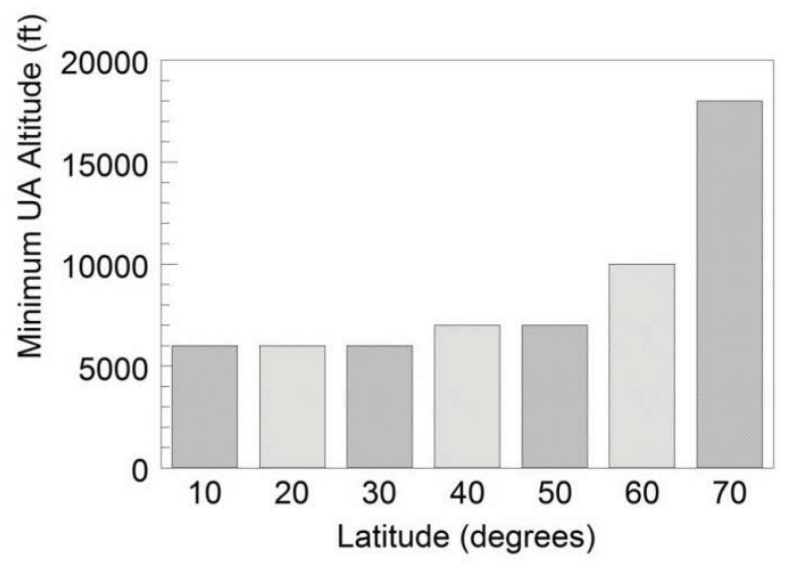

Figure 3. Minimum UA altitude to avoid exceeding $\mathbf{I} / \mathbf{N}$ interference threshold for large $\mathrm{UA}$ antenna at Ku-band.

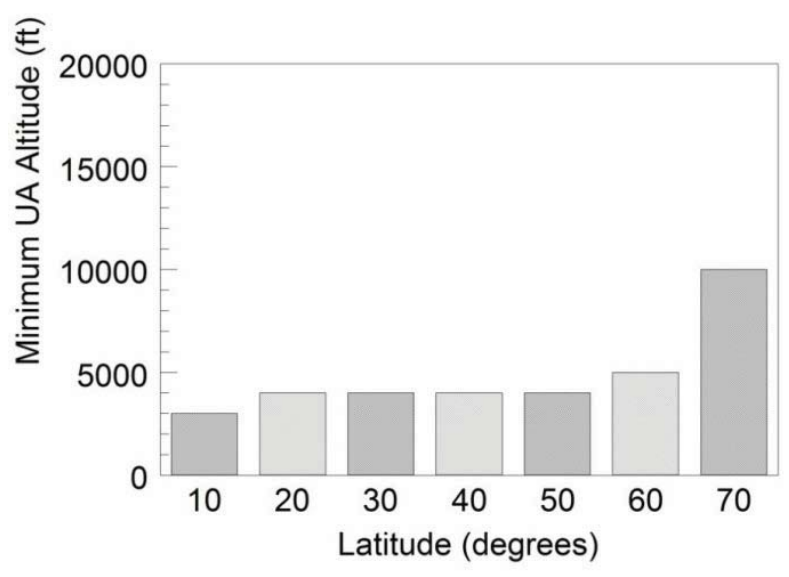

Figure 4. Minimum UA altitude to avoid exceeding I/N interference threshold for small UA antenna at Ku-band.

Changes to these various characteristics and parameters impacting the results of studies are expected. Hence, results shown here are examples and do not necessarily define the final results that will be approved as part of a new ITU-R report that will guide WRC-15 deliberations on AI 1.5.

Nevertheless, the results serve to illustrate the sharing study approach and indicate the complexities of the analysis problem and the differences between long-term interference analyses and short-term interference analyses. These preliminary examples show that while sharing between UAES and FS is emerging as compatible in terms of long-term 
protection criteria, compatibility regarding the shortterm protection criteria is still being determined. Additional modifications to the short-term analyses will be applied to refine the analyses and are expected to impact the results. At upcoming WP5B meetings these latest results will be presented and discussed by the WP5B members to determine where agreement on the results and their application to the resolution of AI 1.5 can be achieved.

\section{Conclusions}

For the integration of UAS into the NAS, protected aviation spectrum for BLOS CNPC is required. Since sufficient radiofrequency spectrum allocations do not currently exist, and there are no existing satellite systems operating in an existing allocation that could be applicable to BLOS CNPC, WRC-15 will consider the possible use of FSS satellites for CNPC. A number of difficult regulatory questions must be addressed in order to enable use of non-aviation-protected spectrum to be used for a protected-aviation spectrum application under WRC15 AI 1.5. To support AI 1.5, studies of sharing between systems in several proposed FSS frequency bands that could be applied to CNPC is required. These studies look at sharing between earth stations operating on UA and terrestrial services operating in the same band, in particular FS stations. The subject of this paper is the study of sharing between UA earth station transmitted and FS receivers.

The sharing studies involve complex analyses considering many parameters such as UA earth station characteristics, FS receive characteristics, antenna radiation patterns, relative signal bandwidths, expected UA densities and operational scenarios. Studies must consider different UA altitudes and FS receivers operating over a range of FS antenna elevation angles operating at a range of latitudes, and must address both short-term and long-term protection criteria. All of these parameters as well as other related criteria are subject to agreement within ITU-R WP5B which is still in process.

This paper has provided background on the sharing studies supporting AI 1.5, the key technical parameters being applied, the analysis approach and example results. The studies will continue to be refined and review and discussion of the results by ITU-R WP5B will occur at upcoming meetings.

\section{References}

[1] ITU-R Report M.2171 - Characteristics of unmanned aircraft systems and spectrum requirements to support their safe operation in nonsegregated airspace.

[2] ITU-R Final Acts, World Radiocommunication Conference (WRC-12) Geneva, 23-January - 17 February 2012.

[3] ITU-R Document 5B/475E, Report on the Twelfth Meeting of Working Party 5B Geneva, 18-29 November 2013.

[4] ITU-R Recommendation F.758-5, System parameters and considerations in the development of criteria for sharing or compatibility between digital fixed wireless systems in the fixed service and systems in other services and other sources of interference, March 2012.

[5] http://transfinite.com/content/Professional. html.

[6] ITU-R Recommendation F.699-7, Reference radiation patterns for fixed wireless system antennas for use in coordination studies and interference assessment in the frequency range from $100 \mathrm{MHz}$ to about $70 \mathrm{GHz}$, April 2006.

[7] ITU-R Recommendation S.580-6, Radiation diagrams for use as design objectives for antennas of earth stations operating with geostationary satellites, January 2004.

[8] ITU-R Recommendation F.1494-0, Interference criteria to protect the fixed service from time varying aggregate interference from other services sharing the $10.7-12.75 \mathrm{GHz}$ band on a coprimary basis, May 2000.

[9] ITU-R Recommendation F.1495-2, Interference criteria to protect the fixed service from time varying aggregate interference from other radiocommunication services sharing the 17.7-19.3 $\mathrm{GHz}$ band on a co-primary basis, March 2012.

\section{Integrated Communications Navigation and Surveillance (ICNS) Conference}

April 8-10, 2014 